\title{
Clivus Rathke cleft cyst: case report of a rare disease and literature review*
}

Cristóbal Langdon 1,2,3, Alfonso Santamaría-Gadea ${ }^{1,2,3}$, María Jesús RojasLechuga ${ }^{1,2}$, Joaquim Mullol',3, Isam Alobid ${ }^{1,2,3}$

'Rhinology Unit and Smell Clinic, ENT Department, Barcelona, Catalonia, Spain

Skull Base Unit; Hospital Clinic, Universitat de Barcelona, Barcelona, Catalonia, Spain

${ }^{3}$ Clinical and Experimental Respiratory Immunology, IDIBAPS, Barcelona, Catalonia, Spain
Rhinology Online, Vol 1: 108 - 111, 2018

http://doi.org/10.4193/RHINOL/18.046

*Received for publication:

August 7, 2018

Accepted: September 11, 2018

Published: September 25, 2018

\begin{abstract}
Background: Rathke's cleft cysts (RCCs) are nonneoplastic epithelial lesions derived from true remnants of the embryological Rathke's pouch. They are commonly located in the sellar and suprasellar region and usually appear as an asymptomatic mass.

Case: A 56-year-old male with a clivus centered isodense mass shown on a CT scan, no bone erosions on the lateral or posterior walls of the clivus, and no compromise of the sella turcica floor. Based on the radiological findings, the most likely diagnosis proposed were chordoma, mucocele, metastatic tumor, Rathke's cyst, Tornwald's cyst or ectopic craniopharyngioma. An endoscopic endonasal trans-sphenoidal approach was done for resection of the lesion. The histopathologic exam revealed a Rathke's cyst. The patient has had an uncomplicated course and remains symptom-free after 12 months follow up.
\end{abstract}

Conclusion: Rathke's cleft cysts (RCCs) are rare exclusive clival lesions, which should be taken into account in the differential diagnosis of clival lesions. It can be surgically treated by an endoscopic conservative way.

Key words: sinonasal tumors, clivus, endoscopic skull base surgery, endonasal approaches, endoscopic sinus surgery, Rathke's cleft cyst

\section{Introduction}

Rathke's cleft cysts (RCCs) are nonneoplastic epithelial lesions of the sellar and suprasellar region. It is believed that they derived from true remnants of the embryological Rathke's pouch ${ }^{(1,2)}$. Theoretically, during the 3rd or 4th week of gestation, a rostral out-pouching of the ectodermal primitive oral cavity meets a downward projection from the neuroectodermal diencephalon. These structures then give rise to the anterior lobe, pars tuberalis, and pars intermedia of the pituitary gland. The residual lumen between the anterior and intermediate lobe constitutes Rathke's cleft. The remnant of Rathke's cleft between the anterior lobe and the pars intermedia can result in an accumulation of fluid and cystic dilation leading to the purely intrasellar RCC or an intrasellar RCC with suprasellar (intrasuprasellar) extension ${ }^{(3)}$. The pars tuberalis lies above the diaphragm, and the Rathke's pouch remnants in this location can give rise to an entirely suprasellar RCC ${ }^{(4)}$. Few authors have classified RCCs based on cyst location and have compared the presentations, different surgical approaches, pathological types, and surgical outcomes ${ }^{(5)}$. To our knowledge, we report the first purely clival $\mathrm{RCC}$ in the literature.

\section{Case report}

A 56-year-old male with no relevant past medical history, no known drug allergies, no prescribed medications, a non-smoker, and a history of mild alcohol use, was recently being assessed for hypogonadism. Due to a CT scan performed during the study of the hypogonadism, which showed a mass isodense centered clivus, the patient was referred to our Rhinology Unit. The lesion had expanded posteriorly and thinned the posterior wall of the clivus, although there was no bone erosions of lateral or posterior walls (Figure 1). The floor of the sella turcica was not affected. There were no remarkable findings on nasal endoscopy, neither on neurologic exploration. Based on the 


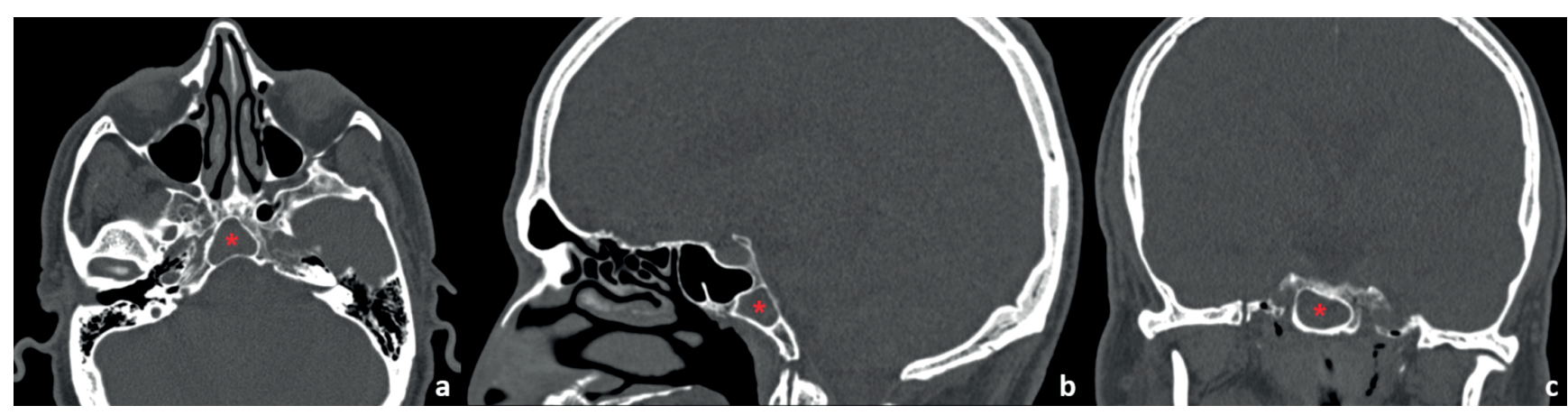

Figure 1. A Rathke's cleft cyst by CT scan imaging (*, bone window). a) axial plane showing a cyst in the body of the clivus with no communication with the sphenoid sinus; b) saggital plane showing thin clivus posterior wall and no communication with sella turcica; and c) coronal plane showing no involvement of carotid canal neither sella turcica.

radiological findings the most likely diagnosis proposed were Tornwald's cyst, chordoma, mucocele, metastatic tumour or ectopic craniopharyngioma.

An endoscopic endonasal trans-sphenoidal approach was done for resection of the lesion. First, the anterior wall of the sphenoid sinus was opened, the mucosa in the sphenoid sinus was thickened, and no sign of mucocele was observed in the sinus. A yellowish viscous fluid was drained through a small bony defect in the anterior wall of the clivus. The hole was opened up with a bone rongeur, and mucinous material and a piece of the brownish membrane of the lesion were removed for bacteriological culture and histological examination. The posterior wall of the clivus was not observed but the dura mater was intact.

The bacteriological culture was negative and the histopathologic exam revealed that the cyst was lined with a single layer of pseudostratified ciliated columnar epithelium with globet cells, no neuroectodermal cells were found. The connective tissue surrounding the epithelium showed mild chronic inflammation (Figure 2). These findings were consistent with a Rathke's cyst. The patient has had an uncomplicated course and remains symptom-free after 12 months follow up.

\section{Discussion}

Rathke's cleft cysts typically present as intrasellar and/or suprasellar cysts, rarely occupying only the suprasellar region ${ }^{(6)}$. In rare occasions, the lesions are intrasphenoidal, with or without lateral extension into the cavernous sinus, or extending into the frontal area. Interestingly, a giant retroclival RCC extending to the lower prepontine cistern with brain stem compression have also been published ${ }^{(7)}$. To our knowledge, we are reporting here the first clival RCC without any duct connecting the cyst with infrasellar or suprasellar structures.

Rathke's cleft cysts are remnants of Rathke's pouch, an ectodermal structure. The Rathke's pouch usually develops during the 4th week of gestation, and prolongs caudally to fuse with the infundibulum around 8th week, forming the craniopharyngeal duct ${ }^{(8)}$. During this time, the Rathke's cleft is formed in the region of the pars intermedia, and normally regresses. The persistence of this cleft can fill with fluid over time, leading to the formation of a RCC ${ }^{(9)}$. The RCC are typically asymptomatic with a slow growth rate. An asymptomatic RCC is most often diagnosed at autopsy with a reported incidence of 5-33\% ${ }^{(10-12)}$. Quite often, over time, some RCCs grow and can become large enough to cause a compressive effect on surrounding structures, resulting in neurological and endocrine abnormalities ${ }^{(13)}$. Some cysts undergo spontaneous resolution ${ }^{(14)}$ while others have reductions in cyst size and symptoms after glucocorticoid treatment ${ }^{(15)}$. The histological analysis usually shows a pseudostratified ciliated columnar epithelium with globet cells with neuroectodermal or pituitary cells. However, this last types of cells were not found in the analysis and we hypothesized that it is because in this case, the cyst has no connection with the sella turcica.

One differential diagnosis to be considered among midline cysts is the Tornwald's cyst, which is a rare congenital cyst present in nasopharyngeal bursa formed by communication between notochord and nasopharyngeal endoderm ${ }^{(16)}$. Most cases are diagnosed in 2nd and 3rd decade of life ${ }^{(17)}$. Patient is usually asymptomatic but may present nasal obstruction, foreign body sensation, halitosis or postnasal discharge ${ }^{(18)}$. The diagnosis of this mass is usually incidental in an imaging test or an autopsy. The main differences between Tornwaldt's cyst and RCC are their location, morphologic findings and the characteristics shown in the image tests ${ }^{(19)}$.

Regarding RCC's treatment, Chotai et al. ${ }^{(5)}$ performed a retrospective review of 87 patients with symptomatic RCCs who had undergone resection; they observed that suprasellar cyst location was an independent predictor of squamous metaplasia and recurrence. The rate of recurrence increased by $17 \%$ in suprasellar cysts with squamous metaplasia, as compared with those without squamous metaplasia. There was a significant association between a suprasellar RCC and a smaller cyst volume $\left(<2.5 \mathrm{~cm}^{3}, \mathrm{p}=0.023\right)$. However, intrasellar RCCs had a 


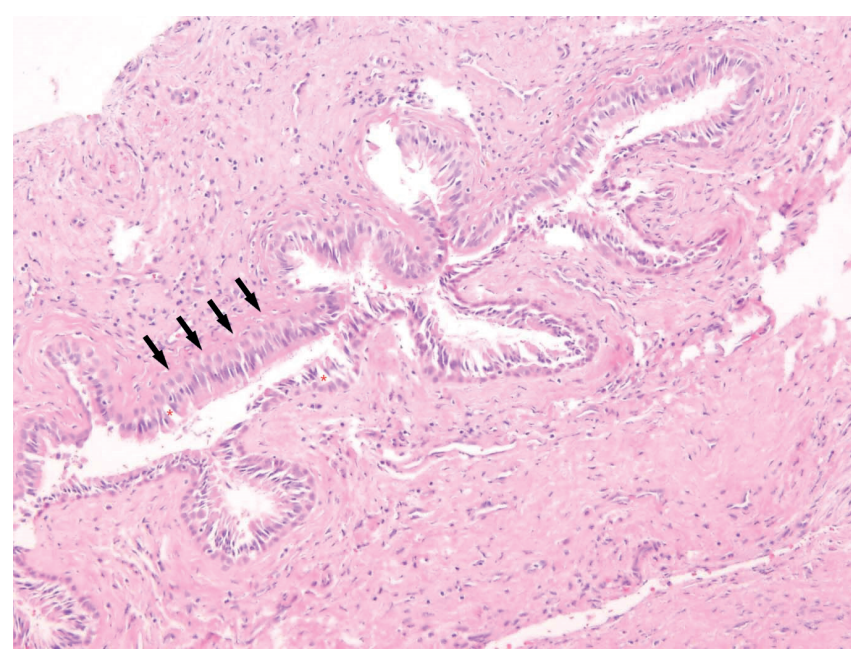

Figure 2. The histopathologic analysis showed a single layer of pseudostratified ciliated columnar epithelium (arrowhead) with globet cells $\left.{ }^{*}\right)$. The connective tissue surrounding the epithelium showed mild chronic inflammation.

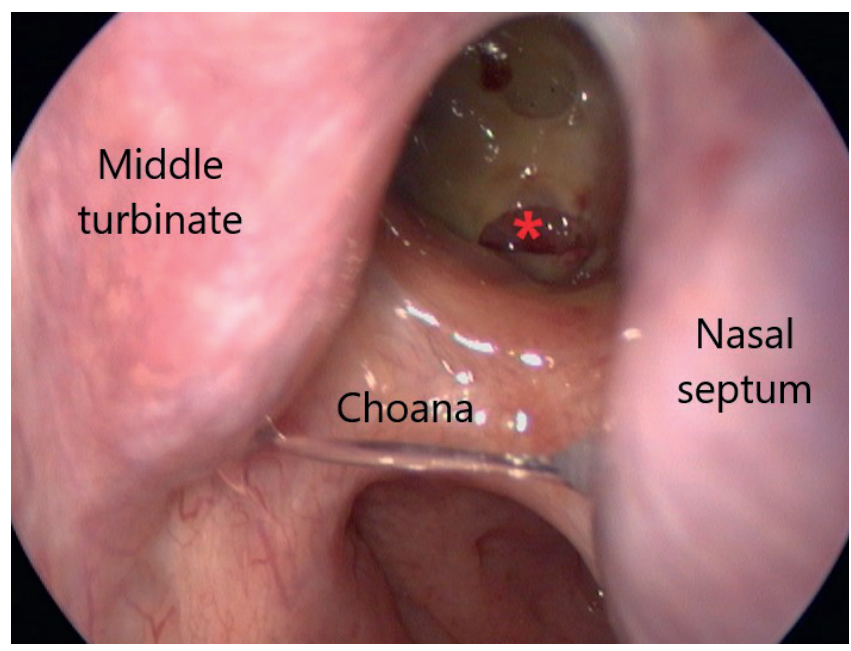

Figure 3. Endoscopic view of the right nasal fossa. The marsupialised cyst to the sphenoid sinus $\left(^{*}\right)$ can be seen. cyst volume $>3.5 \mathrm{~cm}^{3}$ as they remain asymptomatic for a longer period of time, resulting in progressive growth and an increased mean cyst volume.

The surgical treatment of RCC has evolved with newer surgical techniques and a better understanding of the cyst's natural history. Traditionally, transcranial approaches were used with complete excision of the cyst and cyst wall fenestration ${ }^{(20)}$. Few authors have reported a significant association between the extent of cyst resection and recurrence ${ }^{(20,21)}$. However, wide resections have been associated with higher complication rates ${ }^{(22)}$. In the present case report, the patient was free of disease 12 months after endoscopic resection. In the literature review, a microsurgical trans-sphenoidal approach was found to have a higher rate of recurrence (14\% vs. $8 \%$ ) and new endocrine dysfunction ( $25 \%$ vs. $10 \%$ ) compared to the endoscopic approach ${ }^{(23)}$. Since this is the first exclusive clival RCC, we did not perform a radical resection of the cyst because resection of the cyst walls and a big opening in the clivus preserving the posterior wall, was enough for a good drainage and to avoid recurrence.

\section{Authorship contribution}

$\mathrm{CL}$ : Main author of the article. Performed the surgery, ASG: Co-write the article, MJRL: Review of the literature. Review the article, JM: Review the article, IA: Performed the surgery. Review the article.

\section{Conflict of interest}

No conflict of interest.

\section{References}

1. Frazier $\mathrm{CH}$, Alpers BJ. Tumors of Rathke's cleft (hitherto called tumors of Rathke's pouch). Arch Neurol Psychiatry. 1934;32:973-984

2. Ikeda H, Yoshimoto T, Suzuki J. Immunohistochemical study of Rathke's cleft cyst. Acta Neuropathol. 1988;77(1):33 38.

3. Rottenberg GT, Chong WK, Powell M, Kendall BE. Cyst formation of the craniopharyngeal duct. Clin Radiol. 1994;49:126129.

4. Barrow DL, Spector RH, Takei Y, Tindall GT Symptomatic Rathke's cleft cysts located entirely in the suprasellar region: review of diagnosis, management, and pathogenesis. Neurosurgery. 1985;16:766-772.

5. Chotai S, Liu Y, Pan J, Qi S. Characteristics of Rathke's cleft cyst based on cyst location with a primary focus on recurrence after resection. J Neurosurg. 2015;122:1380-1389.

6. Binning MJ, Liu JK, Gannon J, Osborn AG, Couldwell WT. Hemorrhagic and nonhemorrhagic Rathke cleft cysts mimicking pituitary apoplexy. J Neurosurg. 2008;108:3-8.

7. Chuang CC, Chen YL, Jung SM, Pai PC. A giant retroclival Rathke's cleft cyst. J Clin Neurosci. 2010;17:1189-1191.

8. Horvath E, Scheithauer BW, Kovacs K, Lloyd RV. Regional neuropathology: hypothalamus and pituitary. In: Graham DI, Lantos PL (eds): Greenfield's Neuropathology, London: Arnold,1997;1007-1082.

9. Kunwar S, Wilson CB. Cysts, hamartomas and vascular tumours. In: Wass JA, Shalet SM (eds): Oxford Textbook of Endocrinology and Diabetes. Oxford University Press, Oxford: 2002;225-230

10. Steinberg GK, Koenig GH, Golden JB.
Symptomatic Rathke's cleft cysts. Report of two cases. J Neurosurg. 1982;56:290-295.

11. Baskin DS, Wilson CB. Transsphenoidal treatment of nonneoplastic intrasellar cysts. A report of 38 cases. J Neurosurg. 1984;60:813.

12. Shin JL, Asa SL, Woodhouse LJ, Smyth HS, Ezzat S. Cystic lesions of the pituitary: clinicopathological features distinguishing craniopharyngioma, Rathke's cleft cyst, and arachnoid cyst. J Clin Endocrinol Metab. 1999:84:3972-3982.

13. Komatsu F, Tsugu H, Komatsu M, Sakamoto S, Oshiro S, Fukushima T, et al. Clinicopathological characteristics in patients presenting with acute onset of symptoms caused by Rathke's cleft cysts. Acta Neurochir (Wien). 2010;152:1673-1678.

14. Amhaz HH, Chamoun RB, Waguespack SG, Shah K, McCutcheon IE. Spontaneous 
involution of Rathke cleft cysts: is it rare or just underreported?. J Neurosurg. 2010;112:1327-1332.

15. Munich SA, Leonardo J. Spontaneous invoIution of a Rathke's cleft cyst in a patient with normal cortisol secretion. Surg Neurol Int. 2012;3:42.

16. Miyahara H, Matsunaga T. Tornwaldt's disease. Acta Otolaryngol Suppl. 1994;517:36-

17. Jyotirmay $H$, Kumar SA, Preetam $P$, Manjunath D, Bijiraj W. Recent Trends in the Management of Thornwaldts cyst: A Case Report. J Clin Diagn Res. 2014;8:3-4.

18. Marom T, Russo E, Ben Salem D, Roth $Y$. Nasopharyngeal cysts. Int J Pediatr Otorhinolaryngol. 2009;73:1063-70.

19. Conforti R, Sardaro A, Porta ME, Mastellone P, Della Vecchia N, Fontanarosa A et al. MR imaging of the Tornwaldt's cyst: retrospec- tive study of 1300 patients. Recenti Prog Med. 2013;104:398-402.

20. Kim JE, Kim JH, Kim OL, Paek SH, Kim DG, Chi JG, et al. Surgical treatment of symptomatic Rathke cleft cysts: clinical features and results with special attention to recurrence. J Neurosurg. 2004;100:33-40.

21. Han SJ, Rolston JD, Jahangiri A, Aghi MK Rathke's cleft cysts: review of natural history and surgical outcomes. J Neurooncol. 2014;117:197-203.

22. Benveniste RJ, King WA, Walsh J, Lee JS Naidich TP, Post KD. Surgery for Rathke cleft cysts: technical considerations and outcomes. J Neurosurg. 2004;101:577-584.

23. Mendelson ZS, Husain Q, Elmoursi S, Svider PF, Eloy JA, Liu JK. Rathke's cleft cyst recurrence after transsphenoidal surgery: a meta-analysis of 1151 cases. J Clin Neurosci. 2014:21:378-385.
Alfonso Santamaría-Gadea

Rhinology Unit and Smell Clinic

Dept of Otorhinolaryngology

Hospital Clínic

Universitat de Barcelona

c/ Villarroel, 170

Barcelona 08036

Spain

Tel: +34- 932279872

Fax: +34- 932275050

E-mail:

asantamariagadea@gmail.com 